\title{
The Effects of Natural Grass Turf on Some Motoric Characteristics of Young Soccer Players
}

\author{
Atakan Caglayan \\ Correspondence: Atakan Caglayan, Istanbul Gedik University Faculty of Sports Sciences, Istanbul, Turkey.
}

Received: November 16, 2018

Accepted: December 3, 2018 Online Published: December 6, 2018

doi:10.11114/jets.v7i1.3771

URL: https://doi.org/10.11114/jets.v7i1.3771

\begin{abstract}
The aim of this study is to examine the effect of soccer training on natural turfs on strength, speed, power and balance characteristics in prepubertal children. Twenty-two male athletes chosen from the 12-13 age group who play soccer in the youth team of an amateur soccer club from Istanbul, Turkey volunteered to participate in our study. In the study, 30 $\mathrm{m}$ sprint, Y-balance, standing long jump and vertical jump tests were done as pre- and post-tests. The same training program was assigned to the players, who were separated into two groups. One group was trained on synthetic grass turf (SG) while the other group was trained on natural grass turf (NG) for eight weeks. As a result of the statistical analyses, significant improvements were observed in all parameters between pre-and post-test measurements of both SG and NG groups $(\mathrm{p}<0.05)$. When the developmental differences of the groups were examined, statistical improvement was found in the standing long jump parameter in favor of the group that trained on Natural Grass turf $(p=0.037)$. In conclusion, depending on the characteristics of the soccer game, enhancements were observed on both surfaces. However, the challenge effect of natural grass turf was more effective than that of synthetic grass turf on leg strength improvement. It is considered that as a result of continuing their soccer trainings on natural grass turfs, young players can improve their performance and can avoid possible injuries.
\end{abstract}

Keywords: prepuberty, soccer player, balance, speed, strength

\section{Introduction}

Soccer, which is the most popular sports branch in Turkey and the world is a game that requires a high degree of effort and sporting performance and the participants are exposed to actions that have characteristics such as strength, speed, agility, balance, flexibility and sufficient endurance (Helgerud et al., 2001, Bloomfield et al., 2007).

In literature there are numerous training programs aiming at improving sporting performance and these training models improving sporting performance usually consider strength, power and speed exercises (Marques and Gonzales-Bodillo 2006, Kirby et al., 2010). Even though jumping, sprinting and agility are versatile abilities, few publications include the importance of balance, posture or landing mechanisms (Lloyd et al., 2011). In soccer a good balance is a sign of high performance and it plays a significant role in the movements of the soccer player during the game. However, in the studies it is reported that balance and coordination are not fully developed in young players (Chaouachi, 2014). Strength, however, is defined as the maximum resistance that the muscle demonstrates during a slowly performed movement (Wong et al., 2010) and can improve important abilities in soccer such as speed, cutting and speed change (Stolen et al., 2005).

Traditionally, soccer games are played on natural grass turf. Having said that, in many European countries, official synthetic grass games or the use of synthetic grass turf for training is continuously increasing. First-generation synthetic surfaces appeared during the 1970s. These are characterized by a high degree of stiffness and friction with short and thin fibers. Accordingly, this results in significant differences in interactions with the ball. For this reason, synthetic turfs were filled with sand in order to reduce the friction and make the ball bounce less. During the late 1980s second-generation synthetic grasses were longer, were made of thicker fibers, were filled with better quality sand, and rubber foundation was placed underneath to reduce the stiffness (Aune et al., 2003). Since 2005, UEFA and FIFA have approved the use of third-generation synthetic grass in their official tournaments. Also, due to climatic and economic reasons, synthetic grass turfs have become a popular alternative surface (Steffen et al., 2007).

It is reported that in a 60-minute soccer game, young players complete over 30 sprints (meaning faster than $18 \mathrm{~km} / \mathrm{s}$ speed), while the maximum total distance reached with sprints can reach 250 meters (Kanaras et al., 2014, Castagna et 
al., 2003). Today, while the number of young soccer players is increasing, most of the trainings are being done on synthetic grass turfs. However, there are insufficient studies related to the effect of artificial grass on sprint performance while ball handling compared to natural grass in youth soccer team players. Nevertheless, the difference between natural grass and synthetic grass movement patterns and high intensity movements need to be determined. Also, it is valuable to know whether the contacts with the ball and technical standards are affected by the turf floor (Andersson et al., 2008).

Nowadays, synthetic grass turfs are high quality and even similar to natural grass turfs, but it is the nature of soccer to be played on natural grass turf. The performance results comparing trainings made on natural grass and synthetic grass turfs offer limited results with few studies. In some studies, there are findings on the increase of performance of trainings made on synthetic grass (Gains et al., 2010, Potthast, 2010); other studies show no difference in performances between the two surfaces (Ford et al., 2006).

In our study it was hypothesized that while grass turfs by their nature create a soft ground and a better environment to perform technical abilities (ball control, passing ability, shooting and crossing the ball), they can also contribute to the improvement of athletes by creating a natural difficulty for motor skills that require strength. Based on this, the aim of our study is to examine the effect of soccer training on natural turfs on strength, speed, power and balance characteristics in prepubertal children.

\section{Method}

\subsection{Work Group}

Twenty-two male athletes aged $12.00 \pm 1.12$, who play soccer in the youth team of an amateur soccer club in Istanbul, Turkey, joined our study as volunteers. In the study, Y-balance, $30 \mathrm{~m}$ sprint, standing long jump and vertical jump tests were done in that order as pretesting and then the same training program was assigned to the players, who were separated into two groups, then one group (SG) was trained on synthetic grass turf for eight weeks, while the other group (NG) was trained on natural grass turf for eight weeks. After the training program, the young soccer players' post-tests were done. During the pretests the weather was determined at $14^{\circ}$ and during the posttests at $15^{\circ}$ with no rain. Before the tests, dynamic warm-up aimed at the lower extremity was done. Both groups carried out the same traditional soccer training program on natural and synthetic grass turfs.

\subsection{Data Collection Tool and Processing Method}

$30 \mathrm{~m}$ sprint: The 30 Meters Sprint Speed Test is done by placing photocells with 0.01 precision on start and finish points and taking the best of the 2 trials with rest intervals done on a predetermined 30m area on cinder track (Ozer, 2001).

Y-balance test: In order to measure dynamic balance, the Y-Balance test, developed by modifying the Star Excursion Balance Test, was used. Before the test, trials were done with the dominant balance foot for all three directions. The test was done without shoes. The subject stood on one foot on the center of the plate without crossing the red line with their toes, and while standing on one foot, reached towards the anterior, posteromedial and posterolateral directions with the free foot. Three reach tests were done on all directions while standing on the dominant foot. The subject, having their toes behind the red line, stood on the platform and pushed the indicator on the target area. Maximal reach distance was measured by reading the strip measure near the reach indicator. The subject's right leg length was measured from the lowermost anterosuperior iliac to the farthest section of the medial malleolus. Measurement was repeated under the following circumstances: If the other foot touched the floor or the subject fell out of the platform, if the subject kicked the reach indicator, if the subject put their foot on the indicator and used it to support his stance, or if the subject could not return the reach foot back to the starting point (Plisky et al., 2006). The best result for every direction was used for analysis. The sum of maximal data gathered from the three directions was divided by the limb length times three and then was multiplied by one hundred to determine the composite reach distance (composite reach distance $(\%)=$ sum of the 3 reach directions / 3 times the limb length $* 100$ equation) (Shaffer et al. 2013).

Vertical jump test: The reliability of the vertical jump measurement's is between 0.90 and 0.97 . The test is made by Takei (Japan) brand digital jump meter. During the test, the athletes' arms and legs were allowed to swing and the athletes were asked to jump to the highest possible distance with both feet. Measurements were repeated 3 times with a one-minute rest interval given between tests. The best measure was recorded in $\mathrm{cm}$ (Harman and Garhammer, 2008).

Standing Long Jump: A start line was drawn on a flat surface and a tape meter was placed forwards from the start line. The athlete was asked to position himself so that the toes of both feet would be just behind the previously determined line. The athletes were asked to jump forward as far as possible by using their arms and legs and oscillating rapidly while their arms were parallel to the floor and their knees were bent. The jump distance of the athletes was determined by measuring the distance from the starting line to their heel at the point where they landed after they had jumped. The test was repeated three times and the best measure was recorded in $\mathrm{cm}$ (Can et al., 2016). 


\subsection{Statistical Analysis}

The data obtained in the study were analyzed using the SPSS (Statistical Package for Social Sciences) for Windows 21.0 program. The Shapiro Wilks test was used when distributions of the variables were determined and it was found that the distributions were not normal. In the comparison of the quantitative data, Wilcoxon test was used to determine the within-group changes and Mann-Whitney $\mathrm{U}$ test was used for the comparison of parameters between the changes of two groups. The findings were evaluated at $95 \%$ confidence interval and $5 \%$ significance level.

\section{Results}

Table 1. Pre- and Post-Test Analysis of Effect of Synthetic Grass Turf on Standing Long Jump, Vertical Jump, $30 \mathrm{~m}$ sprint and Y Balance Tests

\begin{tabular}{lccccccc}
\hline & \multicolumn{3}{c}{ Pre-Test (n=11) } & \multicolumn{3}{c}{ Post-Test (n=11) } \\
\multicolumn{1}{c}{ Parameters } & Min. & Max. & X \pm SD & Min. & Max. & X \pm SD & p \\
\hline Vertical Jump (cm) & 19.00 & 36.00 & $28 \pm 6.04$ & 22.00 & 41.00 & $32 \pm 7.05$ & $\mathbf{0 . 0 2 1}^{*}$ \\
Standing Long Jump (m) & 1.40 & 2.30 & $1.67 \pm 0.23$ & 1.48 & 2.45 & $1.71 \pm 0.25$ & $\mathbf{0 . 0 3 6}^{*}$ \\
30 m sprint (sec) & 4.55 & 6.09 & $5.44 \pm 1.78$ & 4.13 & 6.00 & $5.34 \pm 1.31$ & $\mathbf{0 . 0 3 2}^{*}$ \\
Y-balance (cm) & 73.99 & 102.19 & $88.11 \pm 8.06$ & 85.87 & 115.62 & $104.39 \pm 16.58$ & $\mathbf{0 . 0 0 2}^{*}$ \\
\hline
\end{tabular}

Min.=Minimum, Max.=Maximum, $\mathrm{p}<0.05^{*}$

When the obtained data were examined, it was seen that the SG players were statistically improved in vertical jump ( $p=$ 0.021), standing long jump ( $\mathrm{p}=0.036), 30 \mathrm{~m}$ sprint $(\mathrm{p}=0.032)$ and Y-balance $(\mathrm{p}=0.002)$ between pre- and post-tests $(\mathrm{p}<0.05)$.

Table 2. Pre- and Post-Test Analysis of Effect of Natural Grass Turf on Standing Long Jump, Vertical Jump, 30 m sprint and Y Balance Tests

\begin{tabular}{lccccccc}
\hline & \multicolumn{3}{c}{ Pre-Test (n=11) } & \multicolumn{3}{c}{ Post-Test (n=11) } \\
\multicolumn{1}{c}{ Parameters } & Min. & Max. & X \pm SD & Min. & Max. & X \pm SD & p \\
\hline Vertical Jump (cm) & 15.00 & 36.00 & $27 \pm 7.06$ & 21.00 & 42.00 & $34 \pm 8.02$ & $\mathbf{0 . 0 1 2}^{*}$ \\
Standing Long Jump (m) & 1.32 & 2.16 & $1.65 \pm 0.13$ & 1.40 & 2.44 & $1.75 \pm 0.12$ & $\mathbf{0 . 0 0 1}^{*}$ \\
30 m sprint (sec) & 5.10 & 6.30 & $5.65 \pm 1.38$ & 4.96 & 6.13 & $5.51 \pm 1.60$ & $\mathbf{0 . 0 2 7}^{*}$ \\
Y-balance (cm) & 81.01 & 109.78 & $90.83 \pm 9.81$ & 92.17 & 128.74 & $111.75 \pm 14.61$ & $\mathbf{0 . 0 0 1}^{*}$ \\
\hline
\end{tabular}

Min.=Minimum, Max.=Maximum, $\mathrm{p}<0.05^{*}$

When the obtained data were examined, it was seen that the NG players were statistically improved in vertical jump $(\mathrm{p}=$ 0.012), standing long jump ( $\mathrm{p}=0.001), 30 \mathrm{~m}$ sprint $(\mathrm{p}=0.027)$ and Y-balance $(\mathrm{p}=0.001)$ between pre- and post-tests $(\mathrm{p}<0.05)$.

Table 3. Assessment of the change scores of Synthetic and Natural Turfs

\begin{tabular}{lccccccc}
\hline \multicolumn{1}{c}{ Parameters } & \multicolumn{3}{c}{ Synthetic (n=11) } & \multicolumn{4}{c}{ Natural $(\mathbf{n = 1 1})$} \\
& Min. & Max. & X \pm SD & Min. & Max. & X \pm SD & p \\
\hline Vertical Jump (cm) & 19.00 & 41.00 & $28.00 \pm 4.05$ & 15.00 & 42.00 & $32.00 \pm 5.45$ & 0.254 \\
Standing Long Jump (m) & 1.40 & 2.45 & $1.62 \pm 0.23$ & 1.32 & 2.44 & $1.68 \pm 0.24$ & $\mathbf{0 . 0 3 7 *}$ \\
30 m sprint (sec) & 4.13 & 6.09 & $5.33 \pm 1.51$ & 4.96 & 6.30 & $5.57 \pm 1.36$ & 0.134 \\
Y-balance (cm) & 73.99 & 115.62 & $105.38 \pm 16.58$ & 81.01 & 128.74 & $110.75 \pm 14.74$ & 0.629 \\
\hline
\end{tabular}

Min. $=$ Minimum, Max. $=$ Maximum, $\mathrm{p}<0.05^{*}$

When the developmental differences of the two groups were evaluated, the NG players showed a statistically significant improvement compared to the SG players in the standing long jump parameter $(\mathrm{p}=0.037)$. No statistically significant difference was found in the other parameters $(\mathrm{p}>0.05)$.

\section{Discussion}

Soccer, by its nature, is played on grass turfs, and these surfaces are generally classified as synthetic or natural turfs (Thomson et al., 2015). It is reported that while synthetic grass turfs have advantages such as being more durable and not being affected by weather conditions, factors such as the stiffness and quality of the surface and its friction with the 
shoes pose a disadvantage and play a key role in injuries (Ekstrand and Nigg, 1989; Orchand, 2002; Williams et al., 2011, Thomson et al., 2015).

In our country, while soccer trainings and competitions are done on natural grass in high level leagues, synthetic grass turfs are often used in non-elite leagues, amateur levels and especially in youth team competitions. Trainings done on natural grass turfs can both create an environment to carry out technical abilities (ball control, passing ability, shooting and crossing the ball etc.) and contribute to athletes' improvement by creating a natural difficulty for abilities that require strength. In the literature, publications regarding the comparisons between the effects of natural and synthetic grass turfs on motoric abilities and technical and tactical aspects cannot be found.

In the present study, as proposed by the hypothesis, it is seen that trainings done on natural grass, compared to trainings done on synthetic grass, show better results on motoric abilities such as standing long jump $(\mathrm{p}<0.05)$.

The dynamic balance characteristic, as examined in our study, is an important aspect to improve sporting performance and carry out the necessary abilities in sporting activities (Ringhof and Stein, 2018, Celenk et al., 2018). In soccer, which is a sport that requires static, semi-dynamic and dynamic balance along with technical abilities (Dunsky et al., 2017), improvements in the non-dominant leg, which is used as the balance leg, can increase the comfort of ball-using abilities and let the athlete carry out the required ability more effectively.

In soccer, in order to carry out a motor activity or carry out activities that require explosive power such as sprinting, shooting, feinting or heading the ball successfully, balance needs to maintain its function against forces disrupting both the external and internal balance (Haghighi et al., 2012, Nikseresht, 2014, Shumway-Hook and Horak, 1986). In order to carry out this function with minimum effort, the transition to the next position needs to be made in a controlled and swift way and the most efficient response needs to be given to the increase in body oscillations as a result of the postural alteration during the ongoing stance (Cobb, 1999). In the present study, with the evaluation of the obtained data, it is seen that young athletes trained on both natural grass turf and synthetic grass turf show statistical improvements in dynamic balance characteristics of their balance legs $(\mathrm{p}<0.05)$. In soccer, by its nature, players stand on one foot while controlling the ball, passing, shooting and dribbling and as a result, this situation might have caused improvements in both groups. Additionally, the young athletes might have fixed their postures against changes caused by the ground in situations specific to the game such as after controlling the ball, passing, and jumping, and this might have had a positive effect. Another study in the literature, that supports the present study, showing the effectiveness of soccer trainings on balance, Jakobsen et al. (2011) reported that the perturbation demands during a 12-week soccer training have effects on improvements in postural balance control.

During recent years, the technical and physical performance parameters in elite soccer players have increased significantly. Players now want to improve their count of passes during a game, explosive sprint abilities, running distances (Thomson et al., 2015) and other motor abilities. In our study, changes in strength and power of athletes were examined with standing long jump and vertical jump strength parameters. According to the data acquired within pre- and post-test results, vertical jump, which is a power indicator, showed significant improvements in both SG and NG soccer players (respectively $\mathrm{p}=0.021$ and $\mathrm{p}=0.012$ ), whereas no statistical difference was observed when the changes between the groups were examined ( $p>0.05)$.

Another parameter we have evaluated in our study was standing long jump, which is an indicator of leg strength. When the pre-post tests were evaluated, statistically significant improvements were observed in both groups $(\mathrm{p}<0.05)$, whereas when the changes between the groups were examined, statistically significant improvements were obtained in the young soccer players who trained on natural grass turf compared to the group who trained on synthetic grass turf $(\mathrm{p}=0.037)$. Nowadays, traditional soccer trainings involve agility, strength and power practices. It is also well known that soccer players enhance their sporting performance with strength trainings (Wong et al., 2010, Ronnestad et al., 2008). In the present study, the strength improvements seen on both natural and synthetic grass turfs can be assessed normally. The fact that the trainings done on natural grass turf showed better results than the trainings done on synthetic grass turf has a compelling effect due to the structural characteristics of natural grass turf. So, it is thought that the natural grass turf is better for young soccer players to strengthen their leg muscles.

In studies done in the literature, there is a high correlation between strength, vertical jump and sprint (Wisloff et al., 2004). In the present study, sprint performance was improved as well as strength and power performance for both NG and SG players. However, for the assessment of sprint performance, in studies done in the literature that compare only the turfs without applying any training protocol, Andersson et al. (2008) did not see a difference between sprints and high-intensity runs done on synthetic grass turf and natural grass turf. In a study done by Gains et al. (2010), in which short sprint and agility tests were compared, the effects of the turfs were also examined. When the effect of the turf was examined, short sprint tests did not show a difference between natural grass turf and synthetic grass turf. In the present 
study, when the pre-post tests for 30m sprint were examined, a statistically significant improvement was seen in both of the groups $(\mathrm{p}<0.05)$, but no significant difference was seen between the change scores of the groups $(\mathrm{p}>0.05)$. In a publication supporting our study, Andersson et al. (2008) did not see a difference between sprint and high-intensity runs in their study with soccer players on synthetic grass turf and natural grass turf.

In publications examining only the sprint performance without applying a training program, soccer players are shown to be able to carry out sprints faster on synthetic grass (Meyers and Barnhill, 2004). It is argued that compared to natural grass turf, the greater force applied on synthetic grass turf results in faster movement ability (Nedelec et al., 2013). Similarly, Kanaras et al. (2014) came to the conclusion that compared to natural grass, children show a better sprint performance on synthetic grass in their research. Even though better results are delivered by athletes on synthetic grass turf especially in straight sprints, stiffness and quality of the surface and friction between the surface and the shoe are key factors in ground-related injuries (Ekstrand and Nigg, 1989; Orchard, 2002).

The sprint is directly associated with strength (Konter, 1998). Magnitude of power, while independent from the size/area of the contact surface, is related with characteristics of the surface. Shiny and smooth surfaces have a lower friction factor. The loss of time during the asymmetrical cuttings specific to soccer on natural grass turfs, with the ball or not, is estimated to be less when compared with synthetic grass turfs. Finally, it can be said that natural grass turfs provide convenience while decelerating, accelerating and cutting.

In conclusion, depending on the characteristics of the soccer game, enhancements were observed on both surfaces. However, the challenge effect of natural grass turf was more effective than that of synthetic grass turf on leg strength improvement. It is considered that, as a result of continuing their soccer trainings on natural grass turfs, young players can improve their performance and avoid possible injuries.

\section{References}

Andersson, H., Ekblom, B., \& Krustrup, P. (2008). Elite football on artificial turf versus natural grass: movement patterns, technical standards, and player impressions. J. Sports Sci., 26, 113-122. https://doi.org/10.1080/02640410701422076

Aune, S., Myhrvold, O., \& Raa, M. K. (2003). Bygging, drift og vedlikehold av kunstgressbaner, Publication no. V-0919. Norway: Lultur—og kirkedepartementet, Norges fotball forbound.

Bloomfield, J., Polman, R., O'Donoghue, P., \& Mcnaughton, L. (2007). Effective Speed and Agility Conditioning Methodology for Random Intermittent Dynamic Type Sports, Journal of Strength and Conditioning Research, 21(4), 1093-1100.

Can, I., Duran, H., \& Songun, Y. (2016). Investigating the Relationship Between Some Performance Parameters and One Repetition Maximal Strength in Trained Athletes, Nigde University Journal of Physical Education and Sport Sciences, 10(3).

Castagna, C., D'Ottavio, S., \& Abt, G. (2003). Activity profile of young soccer players during actual match play. $J$ Strength Cond Res., 17, 775-780.

Celenk, C., Arslan, H., Aktug, Z.B., \& Simsek, E. (2018). The Comparison Between Static and Dynamic Balance Performances of Team and Individual Athletes, European Journal of Physical Education and Sport Science, 4(1).

Chaouachi, A., Othman, B. A., Hammami, R., Drinkwater, E. J., \& Behm, D. G. (2014). The Combination of Plyometric and Balance Training Improves Sprint and Shuttle Run Performances More Often Than Plyometric-Only Training with Children, Journal of Strength and Conditioning Association, 28(2), 401-412. https://doi.org/10.1519/JSC.0b013e3182987059

Cobb, S. V. G. (1999). Measurement of Postural Stability Before and After Immersion in a Virtual Environment, Applied Ergonomics, 30, 47-57. https://doi.org/10.1016/S0003-6870(98)00038-6

Dunsky, A., Barzilay, I., \& Fox, O. (2017). Effect of a specialized injury prevention program on static balance, dynamic balance and kicking accuracy of young soccer players, World J Orthop 2017 April 18; 8(4), 317-321. https://doi.org/10.5312/wjo.v8.i4.317

Ekstrand, J., \& Nigg, B. M. (1989). Surface-related injuries in soccer. Sports Med., 8, 56-62. https://doi.org/10.2165/00007256-198908010-00006

Ford, K. R., Manson, N. A., Evans, B. J., Myer, G. D., Gwin, R. C., Heidt Jr, R. S., \& Hewett, T. E. (2006). Comparison of in-shoe foot loading patterns on natural grass and synthetic turf. J Sci Med Sport, 9, 433-440. https://doi.org/10.1016/j.jsams.2006.03.019 
Gains, G. L., Swedenhjelm, A. N., Mayhew, J. L., Bird, H. M., \& Houser, J. J. (2010). Comparison of speed and agility performance of college football players on field turf and natural grass. Journal of Strength and Conditioning Research, 24(10), 2613-2617. https://doi.org/10.1519/JSC.0b013e3181eccdf8

Haghighi, A., Moghadasi, M., Nikseresht, A., Torkfar, A., \& Haghighi, M. (2012). Effects of Pliometric Versus Resistance Training on Sprint and Skill in Young Soccer Players, European Journal of Experimental Biology, 2(6), $2348-2351$.

Harman, E., \& Garhammer, J. (2008). Administration, scoring, and interpretation of selected tests, In: Beachle TR, Earle RW, Eds. Essentials of Strength Training and Conditioning, 3rd Edition. Champaign, IL. Human Kinetics, 249-292.

Helgerud, J., Engen, L. C., Wisloff, U., \& Hoff, J. (2001). Aerobic Endurance Training Improves Soccer Performance, Medicine and Science in Sports and Exercise, 33, 1925-1931. https://doi.org/10.1097/00005768-200111000-00019

Jakobsen, M. D., Sundstrup, E., Krustrup, P., \& Aagaard, P. (2011). The effect of recreational soccer training and running on postural balance in untrained men. European Journal of Applied Physiology. 111(3), 521-530. https://doi.org/10.1007/s00421-010-1669-2

Kanaras, V. I., Metaxas, T., Mandroukas, A., Gissis, I., Zafeiridis, A. S., Riganas, C., Manolopoulos, E., Paschalis, V. S., \& Vrabas, I. (2014). The Effect of Natural and Artificial Grass on Sprinting Performance in Young Soccer Players. American Journal of Sports Science. 2(1), 1-4. https://doi.org/10.11648/j.ajss.20140201.11

Kirby, T. J., Erickson, T., \& McBride, J. M. (2010). Model for Progression of Strength, Power, and Speed Training, National Strength and Conditioning Association, 32(5), 86 - 90.

Konter, E. (1998). Psychological power and performance in sport, 5th International Sports Science Congress Abstracts, 129.

Lloyd, R. S., Meyers, R. W., \& Oliver, J. L. (2011). The Natural Development and Trainability of Plyometric Ability During Childhood National, Strength and Conditioning Association, 33, 23-32. https://doi.org/10.1519/SSC.0b013e3182093a27

Marques, M. C., \& GonzaLez-Badillo, J. J. (2006). In-Season Resistance Training and Detraining in Professional Team Handball Players, Journal of Strength and Conditioning Research, 20(3), 563-571.

Meyers, M. M., \& Barnhill, B. (2004). Incidence, causes, and severity of high school football injuries on field Turf versus natural grass. American Journal of Sports Medicine., 32, 1626-1638. https://doi.org/10.1177/0363546504266978

Nedelec, M., McCall, A., Carling, C., Le Gall, F., Berthoin, S., \& Dupont, G. (2013). Physical performance and subjective ratings after a soccer-specific exercise simulation: comparison of natural grass versus artificial turf. $J$ Sports Sci., 31, 529-536. https://doi.org/10.1080/02640414.2012.738923

Nikseresht, A., Taheri, E., \& Khoshnam, E. (2014). The Effect of 8 Weeks of Plyometric and Resistance Training on Agility, Speed and Explosive Power in Soccer Players, European Journal of Experimental Biology, 4(1), 383-386.

Orchand, J. (2002). Is there a relationship between ground and climatic conditions and injuries in football? Sports Med., 32, 419-432. https://doi.org/10.2165/00007256-200232070-00002

Ozer, K. (2001). Fiziksel Uygunluk. Nobel Yayin Dagitim, Ankara.

Plisky, P. J., Rauh, M. J., Kaminski, T. W., \& Underwood, F. B. (2006). Star Excursion Balance Test as a predictor of lower extremity injury in high school basketball players. J Orthop Sports Phys Ther, 36(12), 911-919. https://doi.org/10.2519/jospt.2006.2244

Potthast, W. (2010). Motion differences in goal kicking on natural and artificial soccer turf systems, Enhancing performance and protection of soccer shoes, 2(1).

Ringhof, S., \& Stein, T. (2018). Biomechanical assessment of dynamic balance: Specificity of different balance tests, Human Movement Science, 10(58), 140-147. https://doi.org/10.1016/j.humov.2018.02.004

Ronnestad, B. R., Kvamme, N. H., Sunde, A., \& Raastad, T. (2008). Short-term Effects of Strength and Plyometric Training on Sprint and Jump Performance in Professional Soccer Players. J Strength Cond Res., 22(3), 773-780. https://doi.org/10.1519/JSC.0b013e31816a5e86

Shaffer, S. W., Teyhen, D. S., Lorenson, C. L., Warren, R. L., Koreerat, C. M., Straseske, C. A., \& Childs, J. D. (2013). Y-Balance Test: a reliability study involving multiple raters. Mil Med., 178(11), 1264-1270. https://doi.org/10.7205/MILMED-D-13-00222 
Shumway-Cook, A., \& Horak, F. B. (1986). Assessing the Influence of Sensory Interaction of Balance, Physical Therapy, 66(10), 1548-1550. https://doi.org/10.1093/ptj/66.10.1548

Steffen, K., Andersen, T. E., \& Bahr, R. (2007). Risk of Injury on Artificial Turf and Natural Grass in Young Female Football Players, Br J Spor Med, i33-i37.

Stolen, T., Chamari, K., Castagna, C., \& Wisloff, U. (2005). Physiology of Soccer, Review Article, Sports of Medicine, 35(6), 501-536. https://doi.org/10.2165/00007256-200535060-00004

Thomson, A., Whiteley, R., \& Bleakley, C. (2015). Higher shoe-surface interaction is associated with doubling of lower extremity injury risk in football codes: a systematic review and meta-analysis. Br J Sports Med., 0, 1-9. https://doi.org/10.1136/bjsports-2014-094478

Williams, S., Hume, P. A., \& Kara, S. (2011). A Review of football injuries on third and fourth generation artificial turfs compared with natural turf. Sports Med 41(11) 903-923. https://doi.org/10.2165/11593190-000000000-00000

Wisloff, U., Castagna, C., Helgerud, J., Jones, R., \& Hoff, J. (2004). Strong Correlation of Maximal Squat Strength with Sprint Performance and Vertical Jump Height in Elite Soccer Players. British Journal of Sports Medicine, 38(3), 285-288. https://doi.org/10.1136/bjsm.2002.002071

Wong, P., Chamari, K., \& Wisloff, U. (2010). Effects of 12-Week on-field Combined Strength and Power Training on Physical Performance Among U-14 Young Soccer Players. J Strength Cond Res. 24(3), 644-652. https://doi.org/10.1519/JSC.0b013e3181ad3349

\section{Copyrights}

Copyright for this article is retained by the author(s), with first publication rights granted to the journal.

This is an open-access article distributed under the terms and conditions of the Creative Commons Attribution license which permits unrestricted use, distribution, and reproduction in any medium, provided the original work is properly cited. 